\title{
KAJIAN VEGETASI PADA AREA PARKIR KAMPUS
}

\author{
Vivit Rulita Sari ${ }^{1 *}$, Retna Hidayah ,Ph.D ${ }^{2)}$ \\ ${ }^{1)}$ Pascasarjana PTK Konsentrasi Sipil UNY \\ ${ }^{2}$ Universitas Negeri Yogyakarta \\ *Email: vivit.rulita2016@student.uny.ac.id
}

\begin{abstract}
This paper examines the presence of vegetation in the parking area of the UNY campus. The purpose of this study is to know the good criteria for parking area vegetation and to know the benefits of vegetation in the parking area of UNY. The results of the study show that: 1). Vegetation on campus parking area UNY serves as shade, noise absorber, local controller, reducing air pollution, visibility, guide, windbreaker, and animal invited. 2). Good vegetation parking area is non-toxic vegetation, resistant to puddles, animal invited and not a harmful vegetation. 3). Utilization of the island on the parking lot as Bio-retention swale. There is an emphasis on the location of access roads, parking, barriers for vehicles entering in certain areas so that there is no illegal parking or parking is not in place by utilizing vegetation as a barrier for parking.
\end{abstract}

Keywords: parking area, campus vegetation

\section{PENDAHULUAN}

Permasalahan penyediaan lahan parkir serta perencanaanlahan parkir sangat penting untuk dikaji lebih mendalam sebab hampir semua aktivitas kegiatan diruang terbuka memerlukan sarana tempat parkir. Volume kendaraan akan berdampak pada pencemaran lingkungan. Proses pembakaran bahan bakar fosil ini akan menghasilkan emisi yang mengganggu keseimbangan ekosistem di bumi (Ramli Utina,2015). Dengan demikian lahan parkir haruslah didesain ramah lingkungan untuk mengurahi dampak pencemaran lingkungan. Menurut Joko Ariyanto (2016) bahwa dari aspek kegunaannya, vegetasi memiliki kategori kegunan utama yang berbeda-beda. Dengan demikian dengan adanya berbagai jenis vegetasi yang ditanam memunculkan keberagaman potensi kegunaan. Selain itu vegetasi pada lahan parkir dimaksudkan untuk menggantikan sebagian ruang terbuka hijau yang dialihfungsikan menjadi area parkir. Hasil penelitian Joko Ariyanto (2016), juga menjelaskan bahwa vegetasi pada area kampus memiliki kegunaan bervariasi meliputi peneduh, bahan obat, bahan industry,penghasil buah, sayur dan sebagai pagar. Pada hasil penelitian Zulaham (2015) yang mengkaji vegetasi pada fakultas pertanian UGM menyimpulkan bahwa vegetasi area kampus dapat berfungsi sebagai pengendali iklim mikro, identitas dan habitat satwa. Banyaknya kelebihan vegetasi pada area kampus juga dapat dimanfaatkan sebagai vegetasi di area parkir yang ada pada area kampus. Penelitian ini akan mengkaji tentang vegetasi yang ada pada area kampus UNY. Hasil penelitian ini dimaksudkan dapat memberi saran tentang penggunaan vegetasi area parkir yang dapat mendukung open space di wilayah kampus.

\section{METODOLOGI}

\subsection{Lokasi Penelitian}

Kajian tentang vegetasi area kampus UNY dilaksanakan di beberapa titik parkir pada kampus UNY. Terhadap 19 titik parkir pada area kampus UNY, 
19 titik parkir ini teridiri dari 37 titik parkir off street dan 7 titik parkir on street.

\subsection{Sampel dan Populasi}

Pada kajian ini populasi yang akan digunakan adalah vegetasi pada parkiran kampus UNY. Sedangkan pada pengambilan sempel menggunakan metode observasi langsung. Berikut ini ciri sampel yang dianggap mewakili vegetasi pada lahan parkir.

a) Sampel yang diambil merupakan vegetasi penedung yang memiliki tinggi minimal 2 meter saat pengambilan data. Untuk tinggi maksimal tidak disyaratkan secara khusus atau bebas.

b) Tumbuhan yang dijadikan sempel merupakan vegetasi yang berada pada area parkir dan pulau untuk area parkir

c) Vegetasi bukan merupakan tanaman pada area terbuka hijau aktif dan pasif.

d) Diameter batang tidak ditentukan.

\subsection{Analisis Data}

\subsubsection{Identifikasi Vegetasi dengan} App.

Identifikasi vegetasi menggunakan aplikasi PlantNet. Aplikasi ini merupakan aplikasi yang mengidentifikasi vegetasi berdasarkan buah, bunga, struktur daun dan struktur batang. Aplikasi ini digunakan untuk mencari nama ilmiah dari vegetasi yang ditemui.

\subsubsection{Identifikasi vegetasi dengan Internet \\ Internet digunakan untuk meyakinkan data yang didapat dari PlantNet .}

\subsubsection{Analisis Data Berdasarkan Teori}

Analisis data yang ada dikaji berdasarkan teori yang ada dan telah dijabarkan pada bab sebelumnya guna menarik kesimpulan dari seluruh rangkaian kajian yang dilakukan.

\section{HASIL DAN PEMBAHASAN}

Hasil survey dilapangan dilakukan terhadap 19 titik parkir pada area kampus UNY. 19 titik parkir ini teridiri dari 37 titik parkir off street dan 7 titik parkir on street. Dari pengematan lapangan yang telah dilakukan serta pengumpulan data yang ada, diketahui terdapat 51 jenis tanaman dengan jumlah total tanaman sebanyak 1405 pohon.

\subsection{Identifikasi Fungsi Tanaman \\ 3.1.1. Mengurangi pencemar udara (CO2)}

Semua vegetasi yang ada di area parkir kampus UNY merupakan vegetasi yang berfungsi sebagai pengurang pencemaran udara.

\subsubsection{Penyerap Kebisingan}

Vegetasi yang dapat menyerap kebisingan yaitu tanaman tanjung, kiara paying dan pucuk merah.

A. Pembatas Pandang

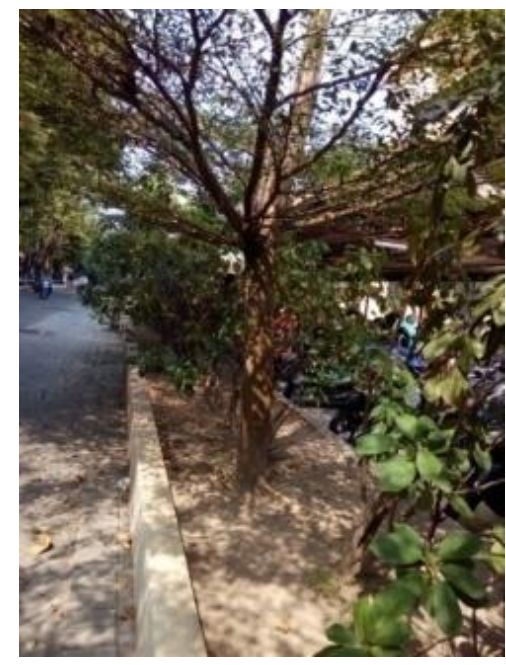

Gambar 1.

Bunga Merah (Ribes Aureum)

B. Pengarah

Vegetasi sebagai pengarah dari penggunaan parkir, dengan 
menggunakan penanaman vegetasi dapat dijasikan sebagai patokan perletakan kendaraan atau tatanan kendaraan pada area parkir. Beriku ini vegetasi yang digunakan sebagai pengarah unutuk penataan parkir.

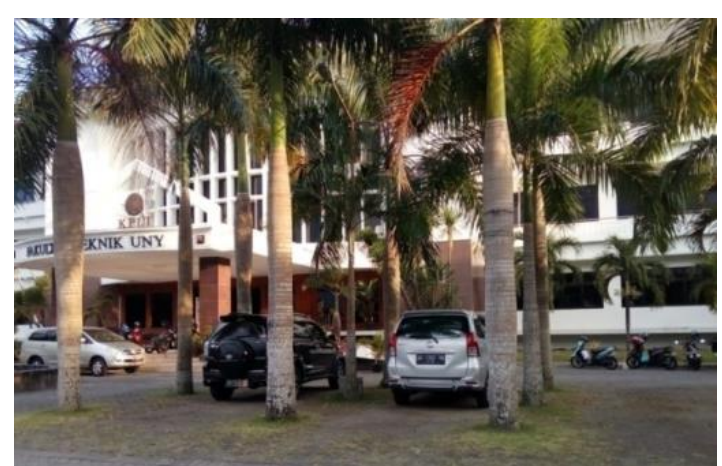

Gambar 2.

Vegetasi sebagai Pengarah

\section{C.Pemecah Angin}

Ciri tanaman yang difungsikan sebagai pemecah angin adalah tanaman yang ditanam secara berbaris atau membentuk massa. Salah satu contoh yang terdapat pada area parkir UNY.

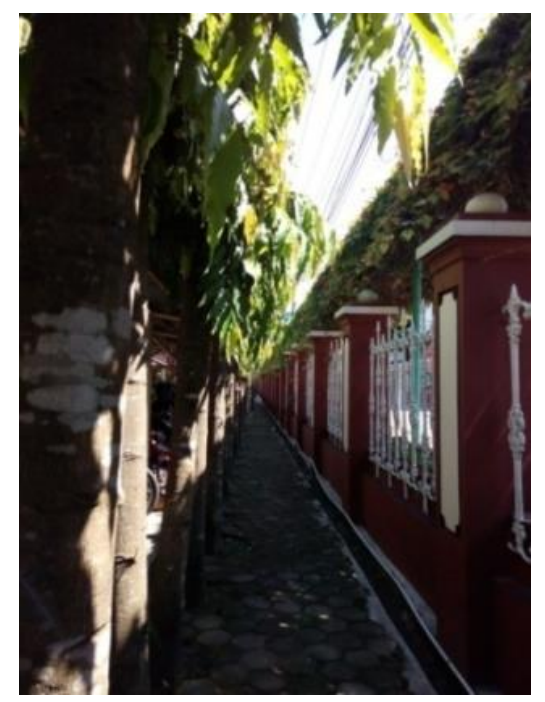

Gambar 3.

Tanaman yang Ditanam Berbaris

D. Vegetasi Berbahaya

Dengan membandingkan kajian teori yang telah ada tentang vegetasi yang berbahaya serta vegetasi yang beracun dengan data vegetasi yang diperoleh, penulis dapat menarik kesimpulan bahwa tidak ada vegetasi berbahaya pada area parkir kampus UNY.

\section{E. Vegetasi Pengundang Satwa}

Vegetasi tidak hanya berfungsi sebagai ruang terbuka hijau, maupun sebagai pengatur iklim. Vegetasi juga merupakan rumah bagi beberapa satwa karean lingkungan vegetasi merupakan lingkungan simbiosis mutualisme. Berikut ini merupakan vegetasi yang ada pada area parkir UNY sebagai vegetasi pengundang satwa berdasarkan kajian teori yang telah ada.

Tabel 1. Pohon Pengundang Burung Pada Area Parkir UNY

\begin{tabular}{cccl}
\hline No & Nama & Nama Ilmiah & Satwa \\
\hline 1 & Kiara & Ficus spp 2 & $\begin{array}{l}\text { Punai } \\
\text { (Treron } s p)\end{array}$ \\
\hline 2 & Beringin & Ficus benyamina & $\begin{array}{l}\text { Punai } \\
\text { (Treron } s p)\end{array}$ \\
\hline
\end{tabular}

F. Vegetasi Tahan Terhadap Genangan Air

Berdasarkan data yang dilapangan dapat diidentifikasi beberapa jenis vegetasi yang terdapat di area parkir UNY yang dapat bertahan pada genangan air.

Tabel 2. Vegetasi Area Parkir UNY yang Tahan Terhadap Genangan Air

\begin{tabular}{llll}
\hline No & $\begin{array}{l}\text { Lama } \\
\text { Genangan }\end{array}$ & Nama & Nama Latin \\
\hline 1 & $10-20$ hari & $\begin{array}{l}\text { Pohon } \\
\text { Salam }\end{array}$ & $\begin{array}{l}\text { Eugeniu } \\
\text { polyantha }\end{array}$ \\
\hline 2 & $40-50$ hari & Pinus & Pinus insularis \\
\hline 3 & $40-50$ hari & Angsana & $\begin{array}{l}\text { Pterocarpus } \\
\text { indicus }\end{array}$ \\
\hline 4 & $70-80$ hari & $\begin{array}{l}\text { Keluarga } \\
\text { Mahoni }\end{array}$ & Swietenia spp. \\
\hline
\end{tabular}

G. Vegetasi sebagai teduhan untuk kendaraan

Vegetasi pada area parkir juga merupakan teduhan yang digunakan sebagai pelindung kendaraan dari sinar matahari yang dapat merusak fisik 
kendaraan. Secara ekonomi, teduhan yang berasal dari vegetasi merupakan alternative yang tepat sebagai pengganti teduhan buatan.

\subsection{Rekomendasi Desain Parkir}

\subsubsection{Jenis Vegetasi}

Untuk memenuhi vegetasi area parkir yang merujuk sebagai ruang terbuka hijau, pengendalian lingkungan, kenyamanan pengguna serta sebagai habitat bagi satwa maka penulis merekomendasikan vegetasi yang dapat ditanam pada area parkir.

Vegetasi yang tahan terhadap genangan air seperti pinus, angsana, sonokeling dan mahoni. Beberapa tanaman tersebut dapat bertahan hidup lebih lama dalam genangan air.

\subsubsection{Tidak menggunakna vegetasi beracun seperti Norium oleander dan Lantana camara}

Dua jenis tanaman ini sangat sering ditemui pada negara tropis .penggunaan tanaman ini ada pada taman, ruang bermain anak, ruang tebuka hijau pasif maupun aktif. Berdasarkan pendapat Thomas (2009) dua jenis tanaman ini merupakan jenis tanaman beracun dan perlu dihindari penggunaannya.

\subsubsection{Vegetasi yang Merugikan}

Menurut Harris dan Dines (1998) yang harus dihindari adalah pinus karena buah pinus dapat membahayakan bagi kendaraan yang terparkir dibawahnya. Namun pinus juga memiliki beberapa keunggulan lain. Namun disarankan untuk tidak digunakan sebagai pencegahan akan kerugian yang ditimbulkan.

Selain pinus pohon beringin juga harus dihindari karena buah pada pohon beringin akan membuat lahan dan kendaraan yang terparkir di bawahnya menjadi kotor akibat buahnya. Buah pohon beringin memiliki karakter yang mirip zat perekat sehingga apabila buah ini jatuh, kemudian mengenai kendaraan yang terparkir maka serpihan buah beringin akan menenpel pada kendaraa dan sulit untuk dibersihkan.

\subsubsection{Vegetasi Pengundang Satwa}

Tabel 3. Jenis Pohon Pengundang Burung

\begin{tabular}{|c|c|c|c|}
\hline No & $\begin{array}{c}\text { Nama } \\
\text { Tanaman }\end{array}$ & $\begin{array}{l}\text { Nama } \\
\text { Latin }\end{array}$ & Jenis Burung \\
\hline 1 & Kiara & Ficus spp2 & $\begin{array}{l}\text { Punai (Treron } \\
\text { sp) }\end{array}$ \\
\hline 2 & Beringin & $\begin{array}{l}\text { Ficus } \\
\text { benyamina }\end{array}$ & $\begin{array}{l}\text { Punai (Treron } \\
\text { sp }\end{array}$ \\
\hline 3 & Loa & $\begin{array}{l}\text { Ficus } \\
\text { glaberrima }\end{array}$ & $\begin{array}{l}\text { Punai (Treron } \\
s p \text { ) }\end{array}$ \\
\hline 4 & Dadap & $\begin{array}{l}\text { Erythrina } \\
\text { varigata }\end{array}$ & $\begin{array}{l}\text { Betet } \\
\text { (Psittacula } \\
\text { alexandri),Sri } \\
\text { ndit } \\
\text { (Loriculus } \\
\text { pusillus) Jalak } \\
\text { (sturnidae) } \\
\text { dan; beberapa } \\
\text { jenis burung } \\
\text { madu }\end{array}$ \\
\hline 5 & Dangdeur & $\begin{array}{l}\text { Gosampinus } \\
\text { heptaphylla }\end{array}$ & $\begin{array}{l}\text { Burung ukut- } \\
\text { ukut } \\
\text { Srigunting }\end{array}$ \\
\hline 6 & Aren & $\begin{array}{l}\text { Arenga } \\
\text { pinatta }\end{array}$ & $\begin{array}{l}\text { Bahan } \\
\text { pembuat } \\
\text { sarang }\end{array}$ \\
\hline 7 & $\begin{array}{l}\text { Kembang } \\
\text { merak }\end{array}$ & $\begin{array}{l}\text { Caesalpinia } \\
\text { pulcherrima }\end{array}$ & $\begin{array}{l}\text { Pengundang } \\
\text { serangga }\end{array}$ \\
\hline
\end{tabular}

Sumber: ( Permen PU tahun 2009 tentang pemanfaatan dan penyediaaan runag terbuka hijau.)

Selain merujuk pada pohon-pohon diatas, area parkir juga harus memiliki pulau pada area perkerasan. Area parkir akan lebih baik memiliki pulau serta vegetasi yang memiliki kemampuan menyerap air. sehingga tidak sampai terjadi genangan pada area parkir. 


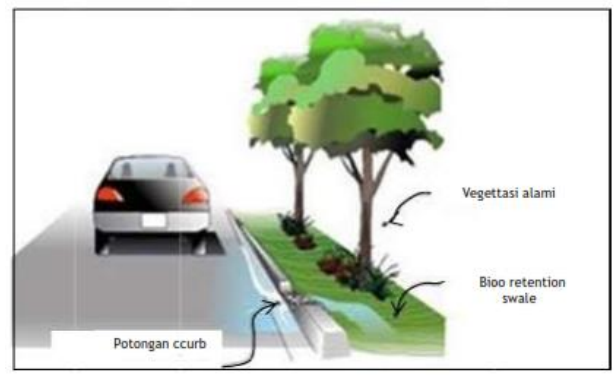

Gambar 4.

Ilustrasi Pemanfaatan Pulau Pada Lahan Parkir Sebagai Bio-retetion swale

Mempertimbangkan keselamatan lingkungan (ekologis). Harus adanya penekanan mengenai lokasi jalan akses, parkir, penghalang bagi kendaraan masuk pada area tertentu agar tidak ada parkir liar maupun parkir tidak pada tempatnya. Hal ini dapat diatasi dengan cara memanfaatkan vegetasi sebagai pembatas untuk parkir.

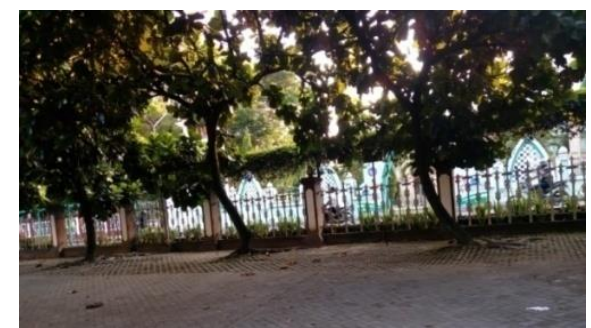

Gambar 5.

Tanaman sebagai Pembatas Parkir.

\subsubsection{Pemilihan Bentuk Tajuk}

Pada parkir area sebaikanya menggunakan tajuk yang beragam hal ini damksutkan agar vegetasi yang ada tidak tumbuh cacat akibat persaingan unruk mendapatkan nutrisi dari sinar matahari. Keberagaman tajuk juga dapat dimanfaatkan sebagai estetika pada lahan parkir. Beriku ini merupakan tajuk yang direkomendasikan pada lahan parkir beserta perletakannya.

\subsubsection{Tajuk Memayung dan Tajuk Menyebar Bebas Untuk On Street.}

Kedua bentuk tajuk ini dapat digunakan sebagai pebatas sekaligus sebagai peneduh untuk kendaraan dan tidak membutuhkan penanaman pohon dengan jarak rapat sehingga dapat digunakan untuk lahan parkir dengan area tanam sempit. Diletakkan pada tepian area dan dapat juga dimanfaatkan sebagai peneduh untuk pejalan kaki.

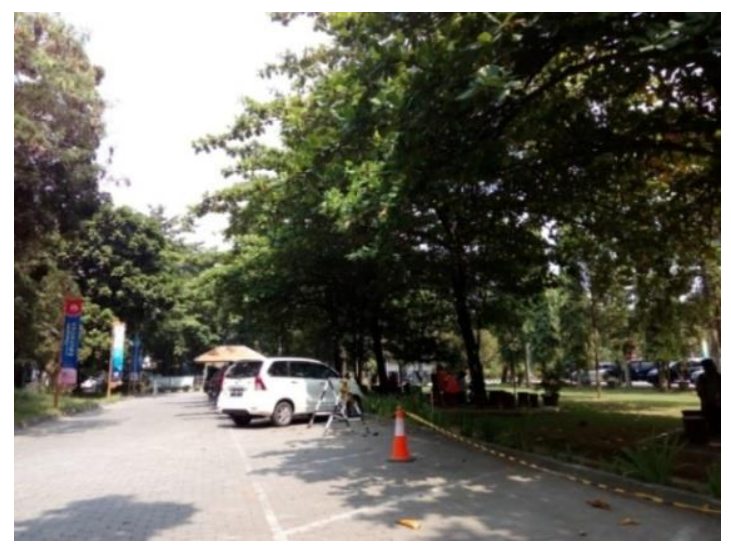

Gambar 5.

Pemanfaatan Vegetasi Bentuk Tajuk Memayung

\subsubsection{Tajuk Bulat, Tajuk Kerucut, Tajuk Segi Empat dan Tajuk Kolom Untuk Off Street.}

Tajuk ini sebaiknya diterapkan pada kantong parkir. Diamana lahan tersebut memang diperuntukkan untuk parkir kendaraan. Penanaman dengan mengkombinasikan bentuk tajuk agar kendaraan dibawahnya dapat terlindungi. Memberikan kesan rindang dan sejuk serta variasi pada lahan parkir. Penanaman vegetasi ditanam pada tepi sekaligus pada lahan parkir sebagai alat untuk penanda area parkir kendaraan.

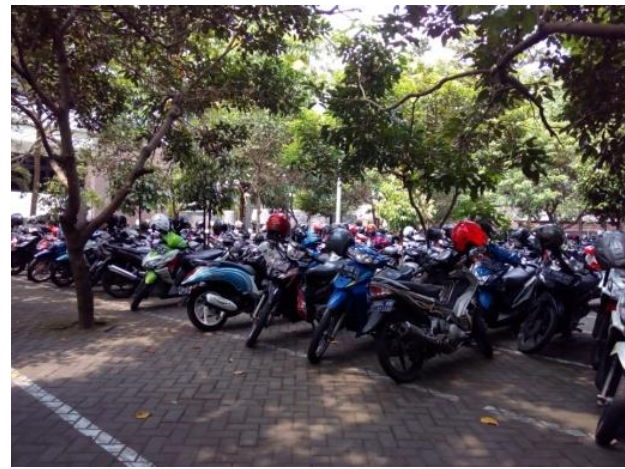

Gambar 6.

Parkir Dengan Tajuk Beragam 


\subsubsection{Satu Jenis Bentuk Tajuk}

Tajuk dengan satu jenis bentuk dapat diaplikasikan pada area parkir on street maupun off street. Satu bentuk tajuk di tampilkan pada gambar 4.12 untuk tajuk memayung pada area parkir on street. Pemilihan vegetasi dengan satu bentuk tajuk dapat digunakan untuk member identitas pada suatu wilayah parkir.



Gambar 7.

Contoh Pemilihan Satu Bentuk Tajuk untuk Parkir

\subsubsection{Memanfaatkan vegetasi sebagai peneduh.}

Desain yang baik merupakan desain dengan menempatkan unsur berdasarkan tujuan dan manfaatnya. Vegetasi dimanfaatkan sebagai peneduh akan mengurangi biaya untuk membangun teduhan yang diperuntukkan bagi area kendaraan di lahan parkir. Serta memberikan efek sejuk pada area parkir kendaraan.

\section{SIMPULAN DAN SARAN}

\subsection{SIMPULAN}

Dari hasil kajian dilapangan dan hasil pembahasan tentang kajian vegetasi pada area parkir kamupus UNY dapat disimpulkan sebagai berikut.

Pada area parkir UNY terdapat 51 jenis tanaman dengan jumlah total tanaman sebanyak 1405 pohon, jumlah terbanyak adalah Glodokan tiang (polyaithia longifolia) yang tersebar di seluruh area parkir UNY.

Area parkir yang baik adalah:

a) Vegetasi yang ditanam tidak beracun, tahan terhadap genangan, pengundang satwa dan bukan merupakan vegetasi yang merugikan.

b) Pemanfaatan pulau pada lahan parkir sebagai Bio-retetion swale.

c) Adanya penekanan mengenai lokasi jalan akses, parkir, penghalang bagi kendaraan masuk pada area tertentu agar tidak ada parkir liar maupun parkir tidak pada tempatnya dengan cara memanfaatkan vegetasi sebagai pembatas untuk parkir.

d) Pemilihan tajuk sesuai dengan fungsi dan tujuan.

e) Penggunaan vegetasi sebagai teduhan alami yang asri dan ekonomis.

\subsection{SARAN}

Selama melakukan kajian dan membahas hasil kajian terdapat beberapa hal yang bisa menjadi masukan atau saran bagi beberapa pihak diantaranya adalah:

a) Diperlukan identifikasi dan penamaan vegetasi yang ada pada area kampus sebagai edukasi sekaligus membantu penelitipeneliti dalam pengambilan data terutama tentang vegetasi .

b) Berdasarkan pada survey lapangan yang menemukan banyaknya lahan alih fungsi dari ruang terbuka hijau menjadi bangunan atau ruang terbuka non hijau seperti lahan parkir maka perlu adanya penelitian tentang ruang terbuka hijau beserta sistem drainasenya.

c) Perlunya penanaman vegetasi pada titik-titik area parkir yang tidak memiliki peneduh kendaraan atau area parkir gersang tanpa vegetasi. 


\section{DAFTAR PUSTAKA}

Jurnal Sugiarto. Kajian Struktur dan Komposisi Pohon di Area Kampus UNS Kentingan Surakarta Sebagai Pendukung Program Green Campus

Ariyanto,J.,Riezky,M \& Nurmiyati. (2016). Identifikasi Jenis dan Manfaat Pohon di Wilayah Kampus Utama Universitas Sebelas Maret. Proceeding Biology Education Conference (ISSN: 2528-5742), Vol 13(1)2016: 711-716.

Utina,Ramli.( $08 \quad$ April 2015).Pemanasan Global : Dampak dan Upaya Meminimalisasinya. Jurnal SAINTEK UNG 2009.

Mentri Perhubungan.(1993).Keputusan Menteri Perhubungan Nomor : KM 66 tahun 1993 tentang Fasilitas Parkir untuk Umum.

Harris,C,W.,\& Dines,N,T. (1998).TimeSaver Standart for Landscape Architecture. Library of Congress Cataloging-in-Publication data.

Jr.L.James. (2007). Site Analysis : a contextual approach to sustainable land planning and site design. Library of Congress Cataloging-inPublication Data: United States of America.

Linch.K. Site Plant. PowePointreview di unduh dari https://www.slideshare.net/.../site- planning-kevin-lynch pada 10 April 2017, pukul 12:02 WIB.

Mochamad,Zulham

Aaron;Ronggomulyo,Rohlan\&

Irwan,Siti.(2015).Kajian Fungsi

Ruang Hijau Fakultas Pertanian

Universitas Gajah Mada. Jurnal

Vegetalika Vol.4 No.1, 2015 : 15 - 28

Pedoman Perencanaan dan

Pengoprasian Fasilitas

Parkir.(1998).Direktorat Jendral

Perhubungan Darat.

Permen PU.(2012). Peraturan Mentri Pekerjaan Umum Nomor : 05/PRT/M/2012. Tentang Pedoman Penanaman Pohon pada Sistem Jaringan Jalan.

Permen PU.(2009). Peraturan Mentri Pekerjaan Umum Nomor: 12/PRT/M/2009. Tentang Pedoman Penyediaan dan Pemanfaatan Ruang Terbuka Non Hijau di Wilayah Kota/Kawasan Perkotaan.

Permen PU.(2008). Peraturan Menteri Pekerjaan Umum Nomor : 05/PRT/M/2008. Tentang Pedoman Penyediaan dan Pemanfaatan Ruang Terbuka Hijau di Kawasan Perkotaan.

Russ.Thomas(2009). Site Planning and Design Handbook. The material in this eBook also appears in the print version of this title: ISBN: 978-0-07160558-8, MHID: 0-07-160558-4. 